\title{
Aziz, Jonker, and Struble are 1995 MRS Fall Meeting Chairs
} November 27-December 1, 1995, Boston, Massachusetts

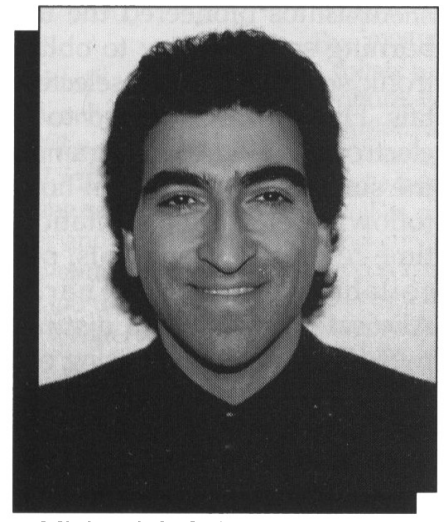

Michael J. Aziz

Michael J. Aziz, Berend T. Jonker, and Leslie J. Struble will serve as meeting chairs for the 1995 MRS Fall Meeting in Boston.

The meeting is comprised of 33 symposia covering a range of cross-disciplinary topics, including a number of strong traditional topics and several new thrusts. Several symposia deal with issues relating to manufacturing and processing. Another theme of the meeting is longterm performance of materials.

Topics of growing interest in MRS include laser processing, polycrystalline thin films, thin films for bioactive applications, self-assembling materials, materials theory, biomaterials, and organic materials (with one symposium on electrical, optical and magnetic properties, and one on long-term performance of polymers). Gallium nitride will be a topic of considerable interest.

New topics appearing at this meeting are electron microscopy studies of dynamic processes, nanostructural effects of surfaces in electronic materials, effects of spontaneous ordering and compositional modulation in electronic materials, microstructural characterization using electrically-based measurements, spectroscopy at heterojunctions, chemistry of energetic materials, and low-cost manufacturing.

The meeting also offers a range of symposia on ion beam-solid interactions, kinetics of phase transformations, epitaxial microstructures, metastable metallic phases, high $\mathrm{T}_{\mathrm{c}}$ superconductors, epitaxial oxide thin films, silicide thin films, diagnostic techniques for semiconductors, MOCVD of electronic ceramics, and diamond for electronic applications. Disordered materials and interfaces, and complex fluids will also be covered, as will cementitious materials, non-oxide ceramics, nuclear waste

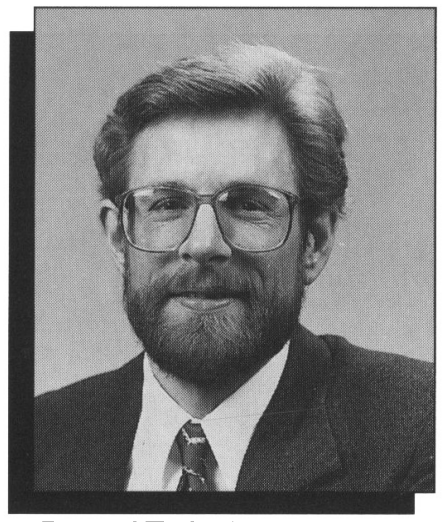

Berend T. Jonker

management, and fullerenes.

Michael J. Aziz is Gordon McKay Professor of Materials Science at Harvard University. A graduate of California Institute of Technology with a BS degree in applied physics, Aziz earned a PhD degree in materials science from Harvard, then spent two years at Oak Ridge National Laboratory as a Eugene P. Wigner Postdoctoral Fellow, before joining the faculty at Harvard. He focuses his research on the kinetics of mass transport in materials processing, including nonequilibrium crystal growth and diffusion.

Aziz is the recipient of an MRS Graduate Student Award, the IBM Faculty Development Award, the Office of Naval Research Young Investigator Award, and the Presidential Young Investigator Award, and he is a Fellow of the American Physical Society.

Aziz has organized two MRS symposia, Fundamentals of Beam-Solid Interactions and Transient Processing (Fall Meeting 1987) and Kinetics of Phase Transformations (Fall 1990). Aziz serves on the MRS Awards Committee.

Berend T. Jonker is a research physicist in the Materials Science and Technology Division of the Naval Research Laboratory (NRL). He received his BS degree in physics from Calvin College in Grand Rapids, MI. Jonker was a guest scientist at NRL from 1984-1986 as a National Research Council Postdoctoral Associate following graduation from the University of Maryland with a PhD degree in physics. His thesis work involved the study of thin-film quantum-size effects in epitaxial systems. He then joined NRL in 1986. Jonker's current research interests center around surface and thin-film magnetism, interface formation and structure of metal and semiconductor epilayers, MBE growth of

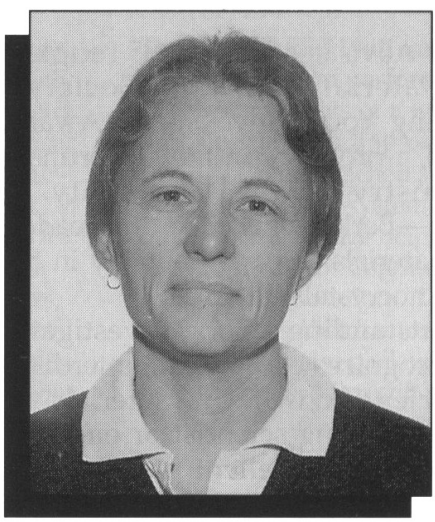

Leslie J. Struble

II-VI wide bandgap semiconductors, and spin-dependent localization and confinement in quantum-well systems.

Jonker is active in several professional societies, including the American Physical Society, the American Vacuum Society, and the Society of Photo-Optical Instrumentation Engineers, and has cochaired MRS symposia on magnetism in ultrathin films in 1989 and 1993.

Leslie J. Struble is an assistant professor in the Department of Civil Engineering at the University of Illinois at UrbanaChampaign, where she is directing research on the flow behavior of cementwater suspensions and of concrete, and on the fracture of hardened cement paste, the durability of concrete railroad ties, and alkali-silica reaction in concrete.

A chemistry graduate of Pitzer College (California), with additional undergraduate studies in geology at the University of California-Riverside, Struble received MS and $\mathrm{PhD}$ degrees in civil engineering from Purdue University. Prior to joining the University of Illinois faculty, she served in research capacities, primarily involved in concrete and cement, at the National Institute of Standards and Technology, Martin Marietta Laboratories, and California Portland Cement Co. (now CalMat Co.).

Struble is active in several professional societies, and has co-chaired two MRS Meeting symposia, Microstructural Development During Hydration of Cement (Fall Meeting 1986) and Flow and Microstructure of Dense Suspensions (Fall 1992). She is editor of Cements Research Progress, an annual publication of the American Ceramic Society, and she is a recipient of the National Science Foundation Young Investigator Award. 